\title{
Fuzzy controlled Modified Switched-Capacitor converter Based LED Driver
}

\author{
${ }^{1}$ Ms. M.Priyanka Gandhi, ${ }^{2}$ Dr. Nishat Kanvel \\ ${ }^{1}$ PG Student, Department of EEE,GCE, Bargur, Tamilnadu, India. \\ ${ }^{2}$ Professor and Head, Department of EEE,GCE, Bargur, Tamilnadu, India. \\ 1'priyakavitha106@gmail.com, ${ }^{2}$ hodeee@gcebargur.ac.in
}

\begin{abstract}
This article discusses a switched capacitor-based converter to drive high power light emitting diodes (LEDs). The current pulse is provided by a switched capacitor, which is differing from that of conventional constant current de drivers. The proposed approach differs from the traditional switched-capacitor-based one, because it uses a small inductor to improve the switching behaviour of the converter. The effects of switching devices on the proposed converter are evidenced and evaluated, based on the charge control analysis.Experimental results are presented and discussed to demonstrate the technical feasibility of the proposed MSC converter applied as LED driver through
\end{abstract} Matlab simulation and hardware result.

Key words: Light emitting diodes, Modified switched capacitor, Variable - frequency constant-current control, Fuzzy logic control method.

\section{INTRODUCTION}

LED drivers require towering performance in addition to multifunctional activities. This LEDs offer high glowing efficiency and lengthylife. The driver is responsible for action of LED. Hence it is essential that the driver must give stunning and economical solution while accompanying a high performance. The lamps must possess the cooler temperatures, longer lifespan, and greater stylistic freedom. This is widely used for nowadays electric vehicles lamp applications. The battery is basic source for electric vehicles. Hence the input current and load current ripples must be small enough so that modified switched capacitor (MSC) converter has been explored to enhance the performance of LED drivers; MSC converter has high-power density, small size, and light weight. Switching losses is high in SC converter and it can be reduced by Modified Switched-Capacitor (MSC) converter. In existing system variable-frequency constantcurrent control (VFCCC) method is used. It has some disadvantages such as by varying frequency method LED bulb blink on and off alternatively, so the load connected get damaged.Fuzzy logicprovides complex mathematical method that allows solving difficult simulatedproblems with many inputs and output variables. In this proposed system Mamdani method is used. Compared to VFCCC method fuzzy logic control more advanced and high efficient controlled.

\section{LITERATURE REVIEW}

(i)This paper proposes the method with the constant ONtime for a switched-capacitor converter-based automotive
LED driver where one-cycle method is basis for control. The analog topology provides regulation for stable load current .The reference value sets the suitable load current. The SC topology is introducedto reduce the current spikes in inductor in the charge loop.(Lei Yang, 2019).(ii) Because Electro-Magnetic Interference (EMI) spectrum is expected and easily mitigated,LED drivers accept Pulse Width Modulation (PWM) for automotive lighting applications Thispaper presents a PWM-based LED driver that features low EMI and high reliability. These attributes are obtained by Average Current Control (ACC and adoption of a dual-phase power stage. (YongQu ,2018), (iii) A proper law will be obtained by way of controlling the related off time of a transistor with the steady on time which is less than the time constant of the price loop. Based on the dynamic capacitor ampere-second balance precept and the one cycle control method, the strong output voltage regulation is done with the fast-dynamic reaction speed. (B. Wu, L. Yang, 2018), (iv) The SC converters are best composed of switches and capacitors. The power transfer is executed by adjusting the charging and discharging periods of the switched capacitors. The resonant switched capacitor converter has been invented to lessen the pulsating current in the price loop and discharge loop of SC converter to comprehend the high power efficiency and the low EMI noise. (P. E. Bolzan, 2018),(v) The LED lamp employs chip-on-board (COB) technology so that it is possible to achieve high power density. The three-phase structure allows low ripple current and reduced percent flicker. In addition it does not use electrolytic capacitors, thus causing the driver lifetime to 
increase. The converter switches gets off under zero current switching (ZCS) and zero voltage switching (ZVS) conditions so that efficiency is consequently increased. (Coutinho, 2017),(vi) The power converter is based on the magnetically coupled Cuk topology. This employs a single, off-the-shelf SMT mutual inductor. No direct sensing of the LED string current is performed, bypassing the disadvantage of the Cuk topology of having an inverted output polarity.(Corradini, 2014).

\section{EXISTING SYSTEM}

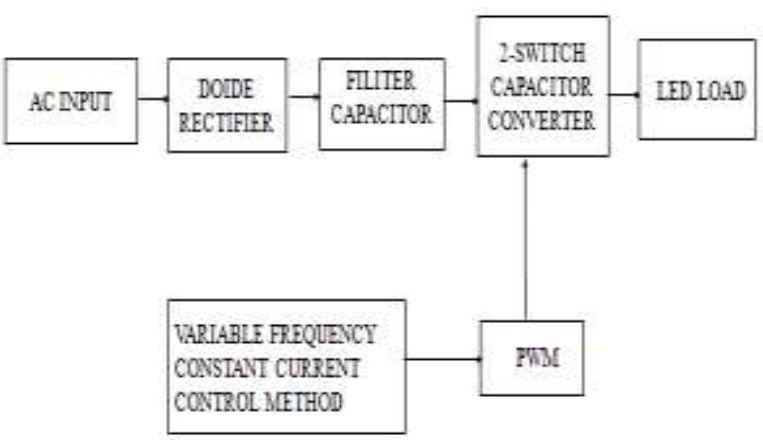

Fig 3.1VFCCC control method

The AC supply is given to the Diode rectifier circuit. This circuit is used to convert AC to DC supply. Switched capacitor and LED driver works in DC supply only. Input capacitor acts as filter block of the circuit. In existing system current spikes is reduced by Switched Capacitor (SC) converter. Variable -frequency constant-current control (VFCCC) method is used. It has some issue that varying frequency results in blink of LED bulb on and off alternatively, so that load connected gets damaged. A fuzzy control method is implemented in this article for a MSC convertered LED driver. Existing System Disadvantages are Variable frequency accruing LED driver load get damaged easily, with the increasing load current, the efficiency will decrease, higher switching loss and higher input current ripple.

\section{IV.PROPOSED SYSTEM}

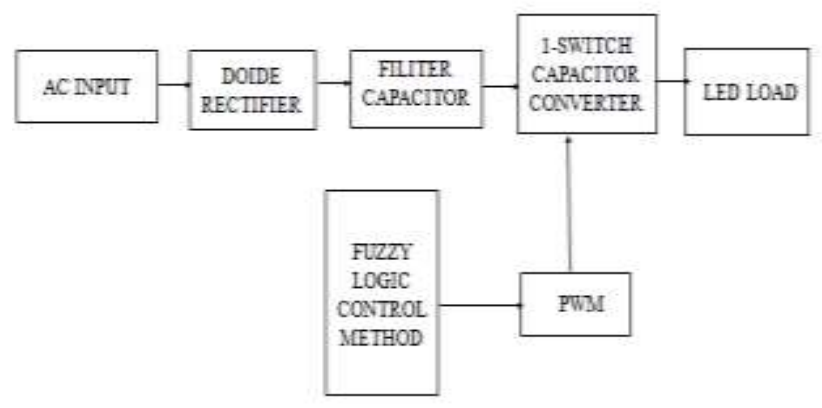

Fig 4.1Fuzzy control method

The input AC supply given to the circuit. Diode rectifier used to convert AC to DC supply. Switched capacitor and LED driver is works in DC supply only. Input capacitor acts as filter block of the circuit. In existing system current spikes gets reduced by Switched Capacitor (SC) converter. Variable -frequency constant-current control (VFCCC) method has some issue that varying frequency method LED bulb blink on and off alternatively, so that load connected gets damaged. In fuzzy logic Mamdani control is used. It has many advantages compared to conventional control methods. That is fast timing response is ensured. Number of switches can be reduced by Modified Switched-Capacitor (MSC) converter. Proposed System Advantages are fuzzy logic control method is used, Variable frequency problems can rejected in this proposed method, Switches can reduce by using MSC converter. MSC converter could provide higher power density, lower price and simpler topology. It provides fast-dynamical response speed with good regulation of LED.

\section{SIMULATION RESULTS}

\subsection{PROPOSED SIMULATION MODEL}

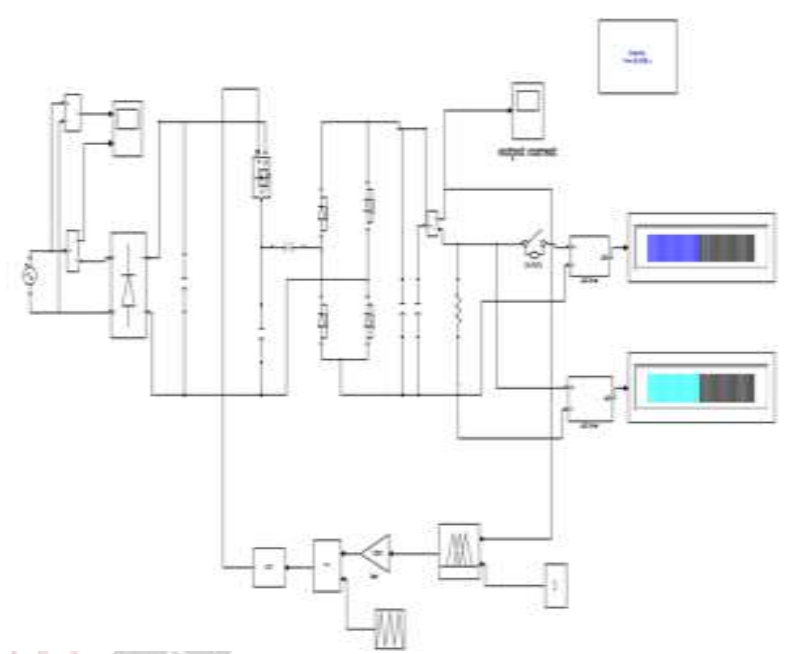

Fig.5.1 Simulink model for proposed system

Figure 5.1 shows the simulation diagram of fuzzy controlled modified switched capacitor converter based automotive LED driver.

\subsection{INPUT WAVEFORM FOR VOLTAGE AND CURRENT}

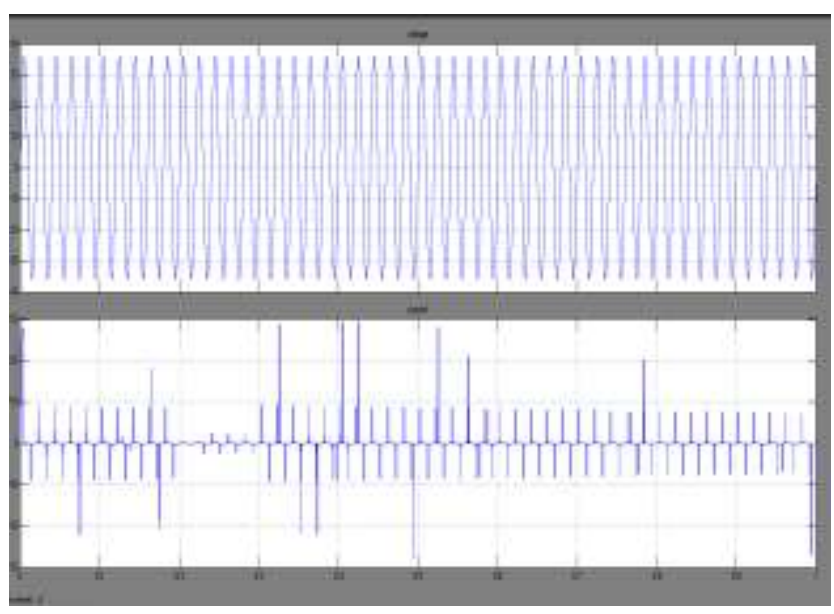

Fig. 5.2 Input waveform for voltage (top) and Current (bottom) 
Fig.5.2 shows input voltage and current waveform of AC voltage sources with respect to time.

\subsection{WAVEFORMOF CONTROLLERS}

Result 1: Existing VFCCC control

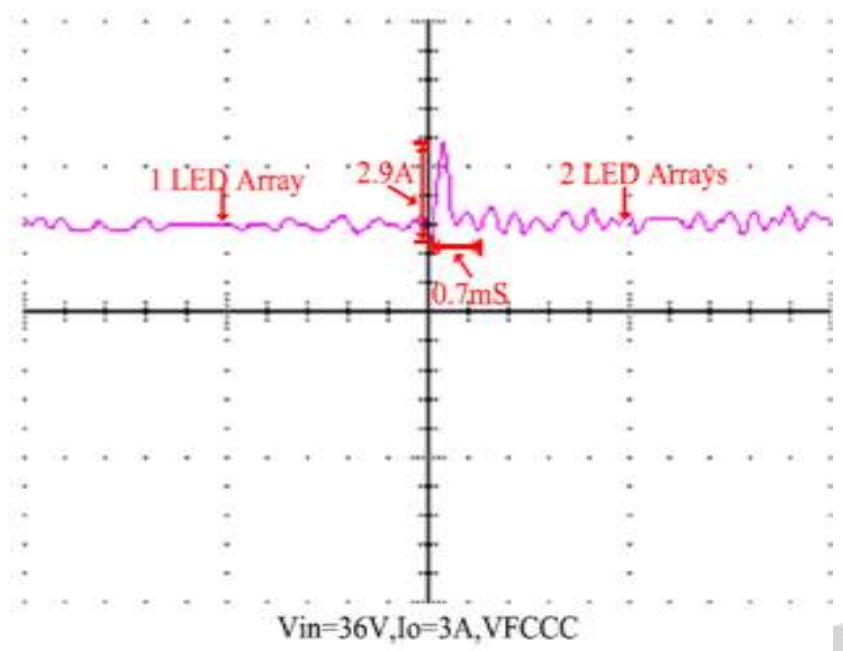

Fig:5.3 Waveform 1: The VFCCC controller provides output waveform which measures the switching time taken for triggering between two LEDs is $0.7 \mathrm{~ms}$ with constant current. Source: Lei Yang, (2019)

Result 2: Proposed fuzzy control

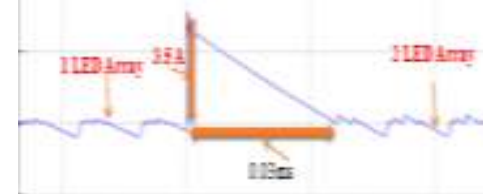

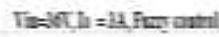

Fig:5.4 Waveform 2: The fuzzy controller provides output waveform which measures the switching time taken for triggering between two LEDs is $0.03 \mathrm{~ms}$ with constant current

\subsection{CONTROLLERS TIMING RESPONSE:}

Table 5.1 Timing priodof VFCCC and Fuzzy controllers

\begin{tabular}{|l|l|l|l|}
\hline S.No & Parameter & $\begin{array}{l}\text { VFCCC } \\
\text { Control } \\
\text { Method }\end{array}$ & $\begin{array}{l}\text { Fuzzy } \\
\text { Control } \\
\text { Method }\end{array}$ \\
\hline 1. & $\begin{array}{l}\text { Timing } \\
\text { Response }\end{array}$ & $0.7 \mathrm{~ms}$ & $0.03 \mathrm{~ms}$ \\
\hline
\end{tabular}

The fuzzy control method provides the timing response with $0.03 \mathrm{~ms}$ which is better than that of VFCCCControl method.

\section{VI.HARDWARE RESULT}

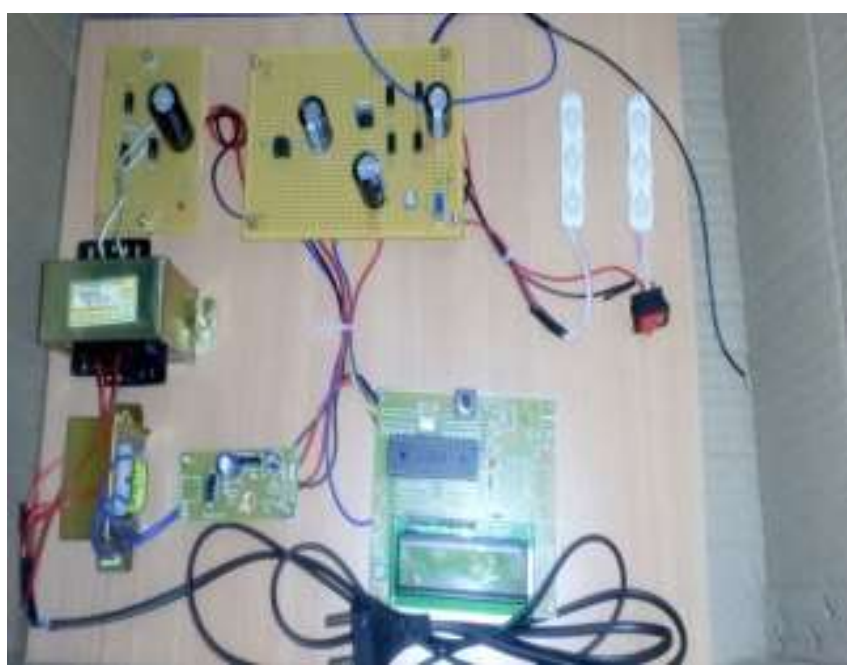

Fig.6.1 Experimental setup for the proposed control method

In hardware proposed package having two transformers is attached for giving input supply. One is furnished via power circuit. In electricity circuit PIC micro controller and LCD display. IC voltage regulator is used provided $5 \mathrm{v}$ supplied by way of transformer. And other transformer provided to control circuit. Here control circuit is Modified Switched Capacitor (MSC) converter. Input 230v is changing to $12 \mathrm{v}$ ac by means of using step down transformer. Input capacitor acts as filter out block. Diode rectifier is used converter $12 \mathrm{v}$ ac to $12 \mathrm{dc}$. Switched capacitor and LED driver is works in DC deliver only. Here fuzzy logic control coding damp into PIC microcontroller via Mplab software. So the experimental hardware results of proposed controller one LED to second LED turn on current is $1.20 \mathrm{~A}$ constantly maintained. The output waveform shown in CRO.

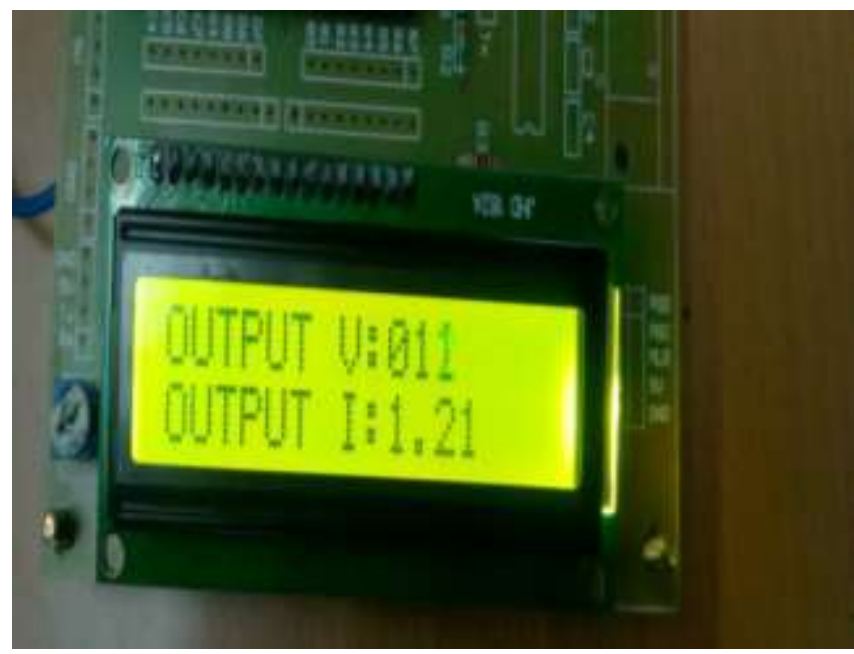

Fig.6.2 The experimental hardware effects of proposed controller one LED to 2nd LED flip on cutting-edge is $1.20 \mathrm{~A}$ continuously maintained. 


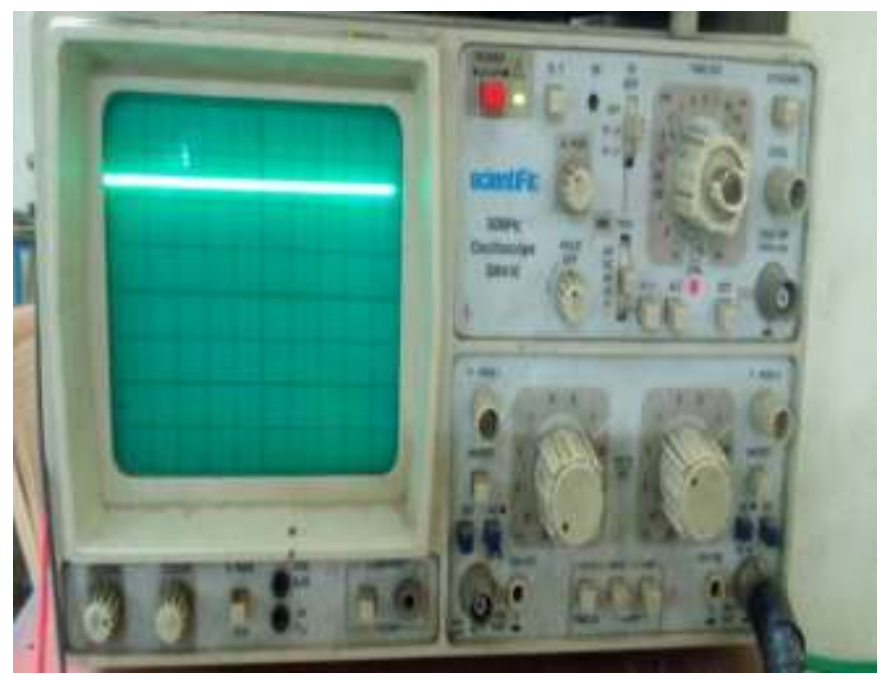

Fig.6.3 CRO output 1.2 A shown the graph

\section{CONCLUSION}

Implementing a fuzzy logic where MSC converter is foundation for automatic LED driver. The MSC converter offers higher energy density, lower price, and simpler topology in comparing with Switched Capacitor converter. Thus enhancing performance and capability of LED drive may be developed by means of the use of fuzzy controlled modified switched capacitor. Fuzzy controller gives speedy timing response is $0.03 \mathrm{~ms}$ in simulation result. Output regular modern can control via fuzzy logic method. The experimental hardware effects of proposed controller one LED to second LED flip on cutting-edge is $1.20 \mathrm{~A}$ continuously maintained. Total Harmonic Distortion (THD) is progressed and offers high efficient output. Variable frequency problems are eliminated in this fuzzy control technique. It assists in LEDs packages of electrical vehicle. There exists a scope of future when that can be implemented the use of new control method and special converter topology will be implemented. To progressed the performance and reduced the cost of LED driver.

\section{REFERENCES}

[1] W. Feng and F. G. Shi, "A new switched-capacitor frequency modulated driver for light emitting diodes," Rev. Sci. Instrum., vol. 78, no. 11, pp. 114701-1114701-4, Nov. 2007.

[2]S. Moon, G.-B. Koo, and W.-G Moon, “'A new control method of interleaved single-stage yback ACDC converter for outdoor LED lighting systems," IEEE Trans. Power Electron., vol. 28, no. 8, pp. 4051 4062, Aug. 2013.

[3] S. K. Ng, K. H. Loo, Y. M. Lai, and C. K. Tse, “Color control system for RGB LED with application to light sources suffering from prolonged aging," IEEE Trans. Ind. Electron., vol. 61, no. 4, pp. 1788-1798, Apr. 2014.

[4] H.-T. Chen, D.-Y.Lin, S.-C. Tan, and S. S. Y. Hui, "Chromatic, photometric and thermal modeling of LED systems with nonidentical LED devices," IEEE Trans.
Power Electron., vol. 29, no. 12, pp. 66366647, Dec. 2014. [5] L. Corradini and G. Spiazzi, "A high-frequency digitally controlled LED driver for automotive applications with fast dimming capabilities," IEEE Trans. Power Electron., vol. 29, no. 12, pp. 6648-6659, Dec. 2014.

[6] H.-T. Chen, S.-C. Tan, and S. Y. Hui, “Nonlinear dimming and correlated color temperature control of bicolor white LED systems," IEEE Trans.Power Electron., vol. 30, no. 12, pp. 69346947, Dec. 2015.

[7] H.-T. Chen, W. C. H. Choy, and S. Y. Hui, "Characterization, modeling, and analysis of organic lightemitting diodes with different structures," IEEE Trans. Power Electron., vol. 31, no. 1,7 pp. 581-592, Jan. 2016.

[8] K. Modepalli and L. Parsa, “A scalable N-color LED driver using single inductor multiple current output topology," IEEE Trans. Power Electron., vol. 31, no. 5, pp. 37733783, May 2016.

[9] Y. Qin, S. Li, and S. Y. Hui, “'Topology-transition control for wide input-voltage-range efficiency improvement and fast current regulation in automotive LED applications," IEEE Trans. Ind. Electron., vol. 64, no. 7, pp. 58835893, Jul. 2017.

[10] R. P. Coutinho, K. C. A. de Souza, F. L. M. Antunes, and E. Sa, “Three phase resonant switched capacitor LED driver with low flicker," IEEE Trans. Ind. Electron., vol. 64, no. 7, pp. 58285837, Jul. 2017.

[11] Y. Wang, J. Alonso, and X. Ruan, “'A review of LED drivers and related technologies," IEEE Trans. Ind. Electron., vol. 64, no. 7, pp. 57545765, Jul. 2017.

[12] Y.Qu, W.Shu, and J. S. Chang, "A low-EMI, highreliability PWM based dual-phase LED driver for automotive lighting,' IEEEJ. Emerg. Sel. Topics Power Electron, vol. 6, no. 3, pp. 1179-1189, Mar. 2018. 